\title{
Mujeres en Ortopedia: listas para el siguiente desafío
}

\author{
Women in Orthopaedic: ready for the next challenge \\ Amparo Gómez Gélvez* \\ *Ortopedista y Traumatóloga. Hospital Universitario de la Samaritana. Bogotá, Colombia.
}

Escribir el editorial de una revista en la que los autores invitados son mujeres ortopedistas era inimaginable a finales del siglo XX. La representación de las mujeres en la residencia de Ortopedia en esa época era mínima; se consideraba que era una especialización apta sólo para hombres, que implicaba fuerza física y rudeza en el ámbito laboral. La exposición de las mujeres a la ortopedia era escasa y no existía ningún modelo a seguir.

En los años 90, algunos programas pioneros en América Latina empezaron a abrirnos sus puertas y a admitirnos como residentes. En ese entonces tuvimos que afrontar con temor, pero con entereza, múltiples desafíos para demostrar que éramos tan aptas como cualquier hombre para desempeñarnos en el mundo de la Ortopedia. La presencia de estas mujeres, referentes iniciales, mostró el camino a seguir para muchas otras; estar dispuestas a estudiar, trabajar duro y capacitarse lo mejor posible eran los principales requisitos que se necesitaban para ser admitidas, sumado a la paciencia para luchar contra la incredulidad, los prejuicios y la discriminación inicial de algunos profesores, compañeros y pacientes.

A partir de entonces, podemos decir con orgullo que nos hemos ganado un espacio en el amplio mundo de la Ortopedia; hoy en día encontramos especialistas mujeres ejerciendo con éxito en todas las subespecialidades, incluyendo las que se consideraban más masculinas, como trauma, columna y cadera. Todavía seguimos siendo minoría, es cierto, pero hemos avanzado en representación, según datos de la International Orthopaedic Diversity Alliance, en la actualidad en México las mujeres ortopedistas representan 9.2\%, en Colombia 9.77\%, en España casi
25\%, mientras que en países como Estados Unidos son $7.6 \%$ y en el Reino Unido sólo $4.8 \%$. En el artículo publicado en 2020 por la misma organización, Estonia es el país del mundo con mayor representación de mujeres ortopedistas, alcanzando $26.4 \%{ }^{1}$

A pesar de que ahora en muchos países las mujeres representan más de $50 \%$ de los estudiantes de medicina, es necesario aumentar su interés por la Ortopedia. La exposición a los problemas del sistema musculoesquelético es mínima en los programas de medicina, si se compara con el estudio de otras patologías como medicina interna o pediatría. Si se conocen los múltiples campos de la ortopedia y encontramos mujeres en posición de liderazgo que además sean mentoras, es posible que aumente el interés y la motivación por escoger Ortopedia como especialidad. La preocupación por compaginar la vida familiar con el ejercicio de una especialidad quirúrgica como la nuestra siempre existe, pero tener el ejemplo de muchas colegas que lo han logrado ayuda a la decisión.

Si bien hemos conseguido entrar con éxito al mundo laboral como ortopedistas, debemos prepararnos para enfrentar el siguiente reto: participar en proyectos de investigación y de innovación que nos permitan generar conocimiento y hacer visible nuestro aporte al avance de la especialidad. Asimismo aumentar la participación en congresos, foros académicos y en la publicación de los resultados de nuestras investigaciones en los diferentes medios disponibles.

El estudio publicado por la British Orthopaedic Association en 2020 sobre la participación de las mujeres ortopedistas en sus congresos entre 20142018 mostró que casi $90 \%$ de las conferencias fueron presentadas por hombres; por otro lado, dentro de las
Correspondencia:

Amparo Gómez Gélvez

E-mail: agomezgelvez@gmail.com
Citar como: Gómez GA. Mujeres en Ortopedia: listas para el siguiente desafío. Orthotips. 2022; 18 (1):6-7. https://dx.doi.org/10.35366/103725 
que fueron presentadas por mujeres, sólo $20.7 \%$ eran sobre temas clínicos (el resto eran sobre educación, temas legales, etcétera) y $18.6 \%$ fueron presentadas en la subespecialidad de pie y tobillo. En cuanto a la participación en los boards editoriales de las revistas de ortopedia, sólo $9.3 \%$ de sus miembros son mujeres. ${ }^{2}$ Aunque no hay estudios en nuestra región, la participación en investigación, innovación y publicación es muy baja en la actualidad.

Por esto la importancia de este primer número de Orthotips en el año 2022, presentamos las investigaciones de colegas de México, España y Colombia sobre diversos temas como osteomielitis del calcáneo, tratamiento de pseudoartrosis con pérdida ósea en fémur, enclavijamiento retrógrado de húmero, controversias en el manejo de lesiones tumorales como el fibroma lipoesclerosante, exposición a radiación en cirugía ortopédica, fracturas del tobillo, liderazgo femenino y el papel de la mujer en investigación.

Investigar, innovar, publicar y ejercer posiciones de liderazgo son desafíos que estoy segura la mayoría de nosotras está dispuesta a afrontar para lograr aportar al avance de la especialidad que nos apasiona y nos mueve a todas.

\section{Referencias}

1. International Orthopaedic Diversity Alliance. Diversity in orthopaedics and traumatology: a global perspective. EFORT Open Rev. 2020; 5 (10): 743-752. doi: 10.1302/20585241.5.200022.

2. Krahelski O, Gallivan S, Hing CB. How well are women represented at orthopaedic conferences? Ann R Coll Surg Engl. 2020; 102 (8): 382-386. doi: 10.1308/rcsbull.2020.206. 